\section{FRI0501 CARDIOVASCULAR DISEASE RISK ASSESSMENT IN PATIENTS WITH FAMILIAL MEDITERRANEAN FEVER RELATED AMYLOIDOSIS}

M. Romano ${ }^{1}$, M. Yilmaz ${ }^{2}$, B. Jackson ${ }^{3}$, C. Acikel ${ }^{4}$, D. Piskin ${ }^{3}$, R. Berard ${ }^{3}$, E. Demirkaya ${ }^{3} .{ }^{1}$ Istituto Ortopedico Gaetano Pini, Milan, Italy; ${ }^{2}$ Epigenetic Health Solutions, Ankara, Turkey; ${ }^{3}$ Western University, London, Canada; ${ }^{4}$ Clinical Research International, Cologne, Germany

Background: FMF is an autosomal recessive disorder. Systemic inflammation in autoinflammatory disorders cause secondary systemic AA amyloidosis, which has been suggested as an important contributing factor to the excess cardiovascular disease (CVD) risk in patients with FMF

Objectives: Our aim was to investigate the CVD-related clinical outcomes in patients with FMF-related amyloidosis and to define risk factors for CVD events (CVDEs).

Methods: A cross-sectional evaluation with prospective follow-up of consecutive patients with FMF-related amyloidosis or other non-diabetic primary glomerulonephropathy (PGN) was performed. Patients were followed for CVDEs. Flow-mediated dilatation (FMD), FGF-23 levels, serum lipid levels, hsCRP, BMI and homeostasis model assessment (HOMA) were assessed. A Cox regression analysis was performed to evaluate the probability of CVDEs associated with each risk factor.

Results: There were 107 patients in FMF-related amyloidosis group and 126 patients with PGN group. Forty-seven CVDEs were registered during the 4.2 years follow up; all 28 patients in the FMF-related amyloidosis versus $14 / 19$ patients with $P G N$ group who developed CVDEs before 40 years of age $(P=0.002)$ (Figure 1). CVD mortality was 2.8 times higher $(95 \% \mathrm{Cl} 1.02-7.76, p=0.03)$ in patients with FMF-related amyloidosis $(n=12)$ than PGN $(n=5)$. Mortality due to CVD was higher in patients less than 40 years old with amyloidosis than PGN ( $12 / 107$ and $3 / 126$ respectively, $R R=4.71,95 \% \mathrm{Cl} 1.36-16.25, \mathrm{p}=0.006)$. Patients with CVDEs had higher levels of proteinuria, hsCRP and FGF23, and lower FMD compared to patients without CVDEs. Across both groups, FGF23 and FMD levels were independently associated with the risk of CVDEs (Table 1).

Conclusion: Patients with FMF-related amyloidosis are at increased risk of CVDEs with early mortality age. These patients should be closely monitored and

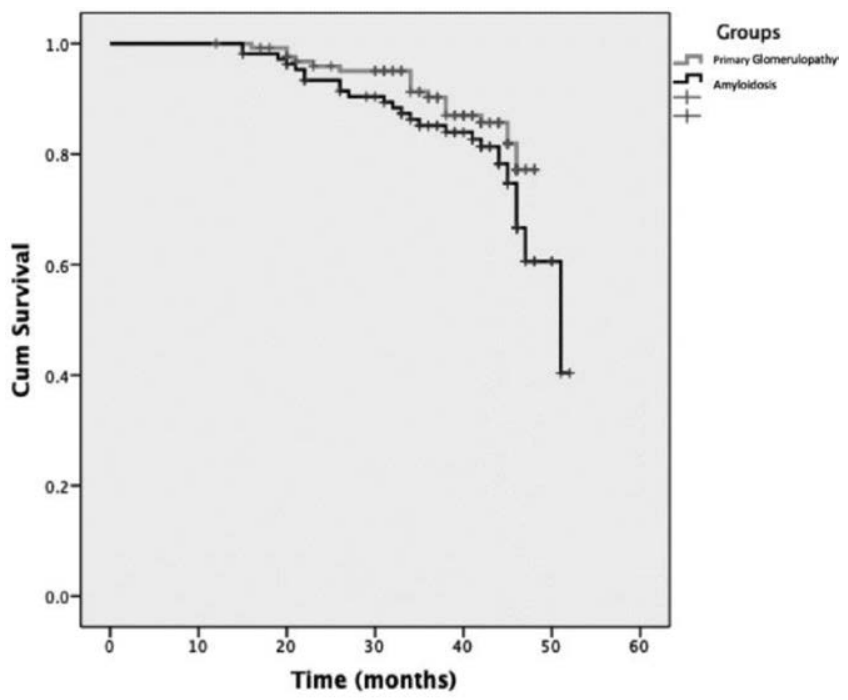

Figure 1. Comparison of cardiovascular disease survival between patients with FMF-related amyloidosis or primary glomerulopathy.

Table 1. Multivariate analysis of factors associated with the risk of suffering a cardiovascular event

\begin{tabular}{lcccccc}
\hline & & B & HR & $\begin{array}{l}95.0 \% \text { Cl for } \\
\text { Exp(B) }\end{array}$ & p \\
& & & \multicolumn{5}{c}{ Lower } & Upper \\
\hline & Variables & & & 1.017 & 1.051 & $<.001$ \\
\hline All Groups & FGF23 & .033 & 1.034 & 1.017 & \\
& FMD & -.946 & .388 & .262 & .575 & $<.001$ \\
Primary & FGF23 & .050 & 1.051 & 1.019 & 1.084 & .002 \\
glomerulopathy & FMD & -.651 & .522 & .300 & .908 & .021 \\
Amyloidosis & FGF23 & .034 & 1.035 & 1.012 & 1.058 & .003 \\
& FMD & -1.531 & .216 & .109 & .430 & $<.001$ \\
& hsCRP & -.040 & .961 & .915 & 1.009 & .108 \\
\hline
\end{tabular}

$\overline{\text { FMD, Flow-mediated dilatation; hsCRP, high sensitivity } \mathrm{C} \text { reactive protein; } \mathrm{Cl} \text {, Confidence }}$ interval if inflammation is poorly controlled with colchicine, biological agents must be added to treatment even if they develop amyloidosis. We also found that hsCRP FGF 23 and FMD levels were the strongest predictors of CVD risk in patients with FMF. These biomarkers can stratify risk of early CVD in patients with FMF-related amyloidosis.

References:

[1] Yilmaz, M.I., et al., Endothelial function in patients with familial Mediterranean fever-related amyloidosis and association with cardiovascular events. Rheumatology (Oxford), 2014. 53(11): p. 2002-8.

Disclosure of Interests: None declared

DOI: 10.1136/annrheumdis-2020-eular.3369

\section{FRI0502 SEASONAL CLUSTERING OF ACUTE SARCOIDOSIS IN GERMANY AND ASSOCIATIONS WITH AIR POLLUTION}

P. Rustler ${ }^{1}$, D. Schindler ${ }^{2}$, R. Voll ${ }^{1}$, F. Kollert ${ }^{3} .{ }^{1}$ Division of Rheumatology and Clinical Immunology, Department of Internal Medicine, University Medical Center Freiburg, Freiburg, Germany; ${ }^{2}$ Environmental Meteorology, University of Freiburg, Freiburg, Germany; ${ }^{3}$ Department of Rheumatology, Immunology \& Allergology (RIA), Inselspital, University Hospital Bern, Bern, Switzerland

Background: Sarcoidosis is a multisystemic granulomatous disorder of unknown origin. The central role of macrophages and granuloma formation, the predominant involvement of lung and skin, and certain risk populations (e.g. firefight$\mathrm{ers}^{1,2}$ ) might be explained by causative airborne antigen $(\mathrm{s})^{3}$. Whether air pollution is involved in pathogenesis and seasonal clustering of sarcoidosis is uncertain. Objectives: This study has been set to analyze seasonal clustering of acute sarcoidosis and associations to air pollution.

Methods: Patients with acute sarcoidosis, defined by bihilar lymphadenopathy, ankle swelling, and/or erythema nodosum plus physician's diagnosis,were included in this retrospective study. Disease onset (seasonal clustering) and associations to air pollution (particulate matter $\left(\mathrm{PM}_{10}\right)$ and nitrogen dixoide $\left(\mathrm{NO}_{2}\right)$ ) were analyzed. Google Trends queries were conducted to address seasonal clustering on a global scale.

Results: A total of 185 patients with acute sarcoidosis were included; $48.7 \%$ of the enrolled patients were female and Löfgren triad was complete in $73.5 \%$ of patients. Acute sarcoidosis clustered from December to June in West Germany ( $p<0.005$, Kendall $\tau=-0.68)$, peaking in January (17.8\% of cases) and in the first third of the year $(54.5 \%)$. Mean $\mathrm{PM}_{1}$ values clustered from December to April with values between 15 and $40 \mu \mathrm{g} / \mathrm{m}^{3}$. $\mathrm{NO}_{2}$ levels were measured highest from November to March $\left(45 \mu \mathrm{g} / \mathrm{m}^{3}\right)$ and lowest between April and August $\left(25 \mu \mathrm{g} / \mathrm{m}^{3}\right)$. Elevated air pollution markers $\left(\mathrm{PM}_{10}\right.$ and $\left.\mathrm{NO}_{2}\right)$ were associated with higher monthly incidence rates of acute sarcoidosis (Cross correlation coefficient ranging between $0.7-0.8$ ). Google Trends analysis yielded seasonal clustering $(p<0.005$, Kendall $\tau=-0.64)$ in winter and spring months on the northern hemisphere.

Conclusion: In Central Europe acute sarcoidosis peaks in winter and spring months (December until March) shortly after $\mathrm{PM}_{10}$ and $\mathrm{NO}_{2}$ maxima are reached. Whether components of particulate matter might be involved in the pathogenesis of sarcoidosis has to be elucidated by further studies.

References:

[1] Prezant DJ, Dhala A, Goldstein A, Janus D, Ortiz F, Aldrich TK, et al. The incidence, prevalence, and severity of sarcoidosis in New York City firefighters. Chest. 1999;

[2] Webber MP, Yip J, Zeig-Owens R, Moir W, Ungprasert P, Crowson CS, et al Post-9/11 sarcoidosis in WTC-exposed firefighters and emergency medica service workers. Respir Med [Internet]. 2017;132:232-7.

[3] Newman LS, Rose CS, Bresnitz EA, Rossman MD, Barnard J, Freder ick $\mathrm{M}$, et al. A case control etiologic study of sarcoidosis: Environmenta and occupational risk factors. Am J Respir Crit Care Med. 2004;170(12) 1324-30.

Disclosure of Interests: Philipp Rustler: None declared, Dirk Schindler: None declared, Reinhard Voll: None declared, Florian Kollert Employee of: Novartis DOI: 10.1136/annrheumdis-2020-eular.4609

\section{\begin{tabular}{|l|l}
\hline FRI0503 VALIDATION OF THE 2019 ACR/EULAR \\
\hline
\end{tabular} CLASSIFICATION CRITERIA FOR IGG4-RELATED DISEASE IN A JAPANESE KIDNEY DISEASE COHORT: A MULTI-CENTER RETROSPECTIVE STUDY BY THE IGG4-RELATED KIDNEY DISEASE (IGG4-RKD) WORKING GROUP OF THE JAPANESE SOCIETY OF NEPHROLOGY}

T. Saeki ${ }^{1}$, M. Kawano ${ }^{2}$, T. Nagasawa ${ }^{3}$, Y. Ubara ${ }^{4}$, Y. Taniguchi ${ }^{5}$, M. Yanagita ${ }^{6}$, S. Nishi ${ }^{7}$, M. Nagata ${ }^{8}$, Y. Yamaguchi ${ }^{9}$, T. Saito ${ }^{10}$, H. Nakashima ${ }^{11}$ on behalf 